\title{
A PANEL STUDY OF SICKNESS PRESENCE AND SICKNESS ABSENCE AMONG SECONDARY SCHOOL STUDENTS
}

\author{
VEGARD JOHANSEN \\ NTNU Norwegian University of Science and Technology, Trondheim, Norway \\ Department of Education and Lifelong Learning
}

\begin{abstract}
Objectives: This article investigates sickness presence among secondary school students in 5 European countries. The research questions asked are: What characterizes students with high sickness presence in secondary schools? Does high sickness presence influence future sickness absence? Material and Methods: A group of 7008 students aged 16-19 years participated in the first study (2016), and 5002 of them also participated in the follow-up study (2017). The participants came from 25 schools in Belgium, Estonia, Finland, Italy and Latvia. The response rate was high. A multivariate binomial logistic regression analysis was used. Results: In 2016 high sickness presence ( $\geq 5$ incidents) was reported by $16 \%$ of the students, and in 2017 by $15 \%$ of them. In 2016 there were significant differences between countries, and students from Latvia were most likely to report high sickness presence (adjusted odds ratio $[\mathrm{aOR}]=3.45)$. Students with high absence $(\mathrm{aOR}=1.86)$ and high school motivation $(\mathrm{aOR}=1.16$, for $1 \mathrm{pt}$ increase on a 5-point scale) were overrepresented among those reporting high sickness presence. Country, absence and motivation were also significant factors for sickness presence in 2017. Furthermore, there was a significant positive association between high sickness presence and high sickness absence the following year. Conclusions: Country, absence, and motivation were important factors for high sickness presence in secondary schools. Engaging in high sickness presence seemed to influence future sickness absence. Int J Occup Med Environ Health. 2019;32(6):797-804
\end{abstract}

Key words:

survey, sickness absence, motivation, sickness presence, logistic regression, secondary school students

\section{INTRODUCTION}

Sickness presence generally refers to attending work while ill. This phenomenon has received increased attention, and previous studies have shown that approximately 60 $70 \%$ of workers in the national samples from Denmark, Norway, Sweden and the Netherlands reported sickness presence [1-4]. Some studies have demonstrated that sickness presence reduces productivity, as illness can affect the quantity of work (e.g., people might work more slowly) and the quality (e.g., people might make more mistakes) [5-7]. Other studies have shown that employees who are often sickness absent also tend to be sickness present, and that high sickness presence can lead to poor health and future high sickness absence [8-14]. Moreover, it has been proposed that organizational/work-related factors and personal factors influence the choice between absence and presence when ill $[1,15,16]$. Personal factors found to influence sickness presence include self-rated health, educational level, gender, age, economic situation, social support, state of work-life balance, and latitude in decision making. Work-related factors found to influence sickness presence include occupational affiliation, job security/in-

Funding: this research was supported by the European Commission (grant No. EACEA 10/2014, entitled "Prospective initiatives, Education and Training," grant manager: Vegard Johansen).

Received: February 6, 2019. Accepted: July 15, 2019.

Corresponding author: Vegard Johansen, NTNU Norwegian University of Science and Technology, Department of Education and Lifelong Learning, Loholt Alle 91, NO-7491 Trondheim, Norway (e-mail: vegard.johansen@ntnu.no). 
security, work burden, working-time arrangements, workplace culture, job satisfaction, control over work tasks, and the potential for adjusting work demands $[1-5,8-16]$.

This article expands the body of research on sickness presence to include secondary school students. To date, only 1 Norwegian study on sickness presence has been conducted among students $(\mathrm{N}=3040)$. In that study, $24 \%$ of the lower secondary school students and $33 \%$ of the upper secondary school students reported high sickness presence during the previous school year (defined as $\geq 4$ incidents). Moreover, the study indicated that girls, students with high school absence, and students with high school motivation reported high sickness presence more often [17].

The present article adds further knowledge on the distribution, determinants, and consequences of high sickness presence among students. Data were collected at 2 points in time from students attending secondary schools in $5 \mathrm{Eu}-$ ropean countries. The data allow an investigation of 2 research questions: What characterizes students with high sickness presence in secondary schools? Does high sickness presence influence future sickness absence?

\section{MATERIAL AND METHODS}

The data were derived from student surveys in Belgium, Estonia, Finland, Italy and Latvia, conducted in 2016 and 2017. The participants in the survey included students aged 16-19 years. The survey was administered to 5 schools in each country, i.e., 25 schools in total. The selection of participating schools was based on having a diverse distribution of the following criteria: education programs (vocational and academic schools), size (small and large schools), and geography (schools in cities and nonurban areas). Each school appointed 1 or 2 contact persons who were responsible for following up on the surveys. On average, 300 students from each school were invited to participate. In the survey round in 2016, 7500 students were invited to participate, and 7008 students responded, yielding an extraordinary response rate of $93 \%$. In the second survey round in 2017, all students participating in the first round were invited (7008 students), and 5002 students responded, yielding a very good response rate of $71 \%$. One reason for fewer students responding in the second round was that some students had left school (e.g., dropped out or continued with an apprenticeship).

The questionnaire was completed online at school. It included questions about school performance, generic skills, key competences, school motivation and effort, absence, sickness presence, and background variables. The research team developed an English version of the questionnaire. This version was professionally translated into Finnish, Italian, Latvian, Flemish (Belgium), Estonian, and Russian (secondary language in Estonia). The online questionnaires were tested by academics, teachers, and students from the participating countries. Based on their feedback and advice, the researchers adjusted the online questionnaires to achieve the highest possible correspondence between the English version of the questionnaire and the translated versions. These pilot studies also ensured that young respondents understood all the questions. The respondents took about $20-25 \mathrm{~min}$ to fill out the questionnaire.

An information letter was provided to students, parents, and teachers. It explained the main purposes of the study, and that it was voluntary to provide responses. It also included contact information for the project leader, including an e-mail address and telephone number. Students who decided not to complete the survey did other school work.

The study was ethically approved by the Norwegian Centre for Research Data. A remit assessment of the project determined that this panel study was not covered by Regional Committees for Medical and Health Research Ethics, but it was necessary to get an approval from the Norwegian Centre for Research Data. The panel study was clarified with the educational ministries in 5 countries 
and the management of the schools where it took place. The students were informed that it was voluntary for them to participate, and they gave an active and written consent by filling out the questionnaire and submitting their responses. The students' parents were informed about the project, both in writing (an information letter) and verbally (school meetings), and they could express their verbal agreement or non-agreement for participation. The Norwegian Centre for Research Data ethically approved this study according to the Personal Data Act, and they approved these methods of actively collecting the consent for participation.

The prevalence of sickness presence was measured by the question: "During the last school year, did you go to school despite feeling so ill that you should have stayed home sick?" The students were presented with 5 alternatives: "No," "Yes, 1 time," "Yes, 2 times," "Yes, 3 or 4 times," "Yes, 5 times or more." High sickness presence was defined as $\geq 5$ incidents. Binary logistic regression was used to detect which factors influenced high sickness presence ( $\geq 5$ incidents). Binary logistic regression is suitable for predicting the outcome of a categorical criterion variable that can take on only 2 possible outcomes [18]. The regression analyses presented in the "Results" section comprised the following independent variables, corresponding with previous studies of sickness presence in school and working life:

- Gender: Divided into male (reference category) and female.

- Age: The lowest age is 16 years and the highest is 19 years.

- Migratory status: Divided into natives (reference category) and immigrants (comprising students born in other countries or both parents born in other countries).

- Parents' education: Divided into students who have parents with low educational attainment (reference category) and students who have parents with high educational attainment (the bachelor's degree or higher).
- Education program: Divided into academic/technical (reference category) and vocational studies. A vocational program generally leads to a craft or journeyman's certificate as well as in-service training with professionals. An academic/technical studies program leads to general university admission certification.

- Sickness absence: Divided into students reporting low or no absence (reference category) and students reporting high sickness absence ( $\geq 15$ days).

- School motivation: A scale variable ranging from 1 (low motivation) to 5 (high motivation) was used. This is a standardized index and based on 4 variables measuring general interest in school, whether the student likes doing school work, likes various subjects, and enjoys going to school. The reliability was good (Cronbach's $\alpha$ was 0.84) [18].

- Country: Divided into Finland (reference category), Belgium, Estonia, Italy and Latvia.

\section{RESULTS}

Table 1 displays information about the distribution of sickness presence episodes. In total, $79 \%$ of the respondents in 2016 and $80 \%$ in 2017 responded that they had gone to school even though it would have been reasonable to stay at home sick. High sickness presence ( $\geq 5$ incidents) was reported by $16 \%$ of the students in 2016 and by $15 \%$ in 2017. There were notable differences between the countries; Latvia had the highest proportion of students reporting high sickness presence, whereas the proportions were significantly lower for Belgium and Finland.

Table 2 shows odds ratios (OR) and p-values from 2 multivariate logistic regression models of factors predicting high sickness presence in 2016 and 2017. The results were adjusted for the other possible factors. Both models demonstrated statistically significant correlations ( $p<0.05$ ) for "age," "high sickness absence," "school motivation," and country variables. The "immigrant" 
Table 1. Sickness presence incidents among students in 25 secondary schools in Belgium, Estonia, Finland, Italy and Latvia, in $2016(\mathrm{~N}=6982)$ and $2017(\mathrm{~N}=4982)$

\begin{tabular}{lcccccc}
\hline $\begin{array}{c}\text { Sickness presence } \\
\text { incidents }\end{array}$ & \multicolumn{7}{c}{$\begin{array}{c}\text { Subjects } \\
{[\%]}\end{array}$} \\
\cline { 2 - 6 } \multicolumn{1}{c}{ Total } & Belgium & Estonia & Finland & Italy & Latvia \\
\hline 2016 & & & & & \\
0 times & 21 & 24 & 19 & 28 & 16 & 16 \\
$1-4$ times & 63 & 69 & 60 & 61 & 69 & 57 \\
$\geq 5$ times & 16 & 7 & 21 & 11 & 15 & 27 \\
2017 & & & & & & \\
0 times & 20 & 22 & 20 & 28 & 15 & 14 \\
$1-4$ times & 65 & 71 & 61 & 61 & 70 & 60 \\
$\geq 5$ times & 15 & 7 & 19 & 11 & 15 & 26 \\
\hline
\end{tabular}

Table 2. Binary logistic regression of the factors influencing high sickness presence ( $\geq 5$ episodes) among students in 25 secondary schools in Belgium, Estonia, Finland, Italy and Latvia

\begin{tabular}{|c|c|c|c|c|c|c|}
\hline \multirow{2}{*}{ Variable } & \multicolumn{3}{|c|}{2016} & \multicolumn{3}{|c|}{2017} \\
\hline & $\mathrm{aOR}$ & $95 \% \mathrm{CI}$ & $\mathrm{p}$ & $\mathrm{aOR}$ & $95 \% \mathrm{CI}$ & $\mathrm{p}$ \\
\hline Age & 1.09 & $1.02-1.19$ & $*$ & 1.12 & $1.02-1.23$ & * \\
\hline \multicolumn{7}{|l|}{ Gender } \\
\hline male & 1.00 & & & 1.00 & & \\
\hline female & 0.95 & $0.83-1.08$ & & 0.97 & $0.82-1.15$ & \\
\hline \multicolumn{7}{|l|}{ Migratory status } \\
\hline native & 1.00 & & & 1.00 & & \\
\hline immigrant & 1.25 & $0.98-1.60$ & & 1.33 & $1.01-1.76$ & * \\
\hline \multicolumn{7}{|l|}{ Parents' education } \\
\hline low & 1.00 & & & 1.00 & & \\
\hline high & 1.01 & $0.89-1.16$ & & 1.02 & $0.86-1.20$ & \\
\hline \multicolumn{7}{|l|}{ Education program } \\
\hline academic/technical studies & 1.00 & & & 1.00 & & \\
\hline vocational studies & 0.96 & $0.83-1.10$ & & 0.92 & $0.75-1.22$ & \\
\hline \multicolumn{7}{|l|}{ Sickness absence } \\
\hline no/low & 1.00 & & & 1.00 & & \\
\hline high & 1.86 & $1.61-2.14$ & $* *$ & 2.12 & $1.77-2.55$ & $* *$ \\
\hline School motivation & 1.16 & $1.07-1.26$ & $* *$ & 1.18 & $1.05-1.33$ & $* *$ \\
\hline \multicolumn{7}{|l|}{ Study country } \\
\hline Finland & 1.00 & & & 1.00 & & \\
\hline Belgium & 0.73 & $0.53-1.02$ & & 0.99 & $0.71-1.39$ & \\
\hline
\end{tabular}


Table 2. Binary logistic regression of the factors influencing high sickness presence ( $\geq 5$ episodes) among students in 25 secondary schools in Belgium, Estonia, Finland, Italy and Latvia. - cont.

\begin{tabular}{|c|c|c|c|c|c|c|}
\hline \multirow{2}{*}{ Variable } & \multicolumn{3}{|c|}{2016} & \multicolumn{3}{|c|}{2017} \\
\hline & $\mathrm{aOR}$ & $95 \% \mathrm{CI}$ & $\mathrm{p}$ & $\mathrm{aOR}$ & $95 \% \mathrm{CI}$ & $\mathrm{p}$ \\
\hline \multicolumn{7}{|l|}{ Study country - cont. } \\
\hline Estonia & 2.19 & $1.69-2.85$ & $* *$ & 1.53 & $1.14-2.06$ & $* *$ \\
\hline Italy & 1.58 & $1.25-2.02$ & $* *$ & 1.59 & $1.17-2.56$ & $* *$ \\
\hline Latvia & 3.45 & $2.79-4.27$ & $* *$ & 2.65 & $2.01-3.50$ & $* *$ \\
\hline
\end{tabular}

* Significant at 0.05 .

** Significant at 0.01 .

status was significant in the 2017 study, but it was nonsignificant in the 2016 study. The remaining variables were non-significant in both models. In addition to country differences, the most influential factor was absence; students with high sickness absence from school were 1.9 times (2016) and 2.1 times (2017) more likely to report high sickness presence compared to those with low/ no sickness absence.

Table 3 shows odds ratios (OR) and p-values from a multivariate logistic regression of factors predicting high sickness absence in 2017. The results were adjusted for the other possible factors. The analysis demonstrated statistically significant correlations $(p<0.05)$ for "female," "high sickness absence in 2016," "high sickness presence in 2016," "school motivation," "vocational studies," and country variables. The remaining variables were non-significant. There was a strong correlation between high sickness absence in 2017 and high sickness absence in the previous school year; students with high sickness absence in 2016 were 5.1 times more likely to report high sickness absence in 2017 compared to those with low/no sickness absence in 2016. A high level of sickness presence in 2016 influenced sickness absence in the following year; students with high sickness presence in 2016 were 2.1 times more likely to report high sickness absence in 2017 compared to those with low/no sickness presence in 2016.

\section{DISCUSSION}

Most students in each of the 5 countries investigated reported sickness presence in a school year. This finding was in accordance with previous studies of sickness presence among adult workers [1-5] and among secondary school students in Norway [17]. The present study found that $15 \%$ and $16 \%$ of the students reported high sickness presence ( $\geq 5$ incidents) for 2016 and 2017, respectively.

Some of the country differences regarding sickness presence could be related to regulations or guidelines regarding school attendance. The prevalence of high sickness presence was the highest in Latvia, a country which has very strict attendance requirements. When asked about the reasons for sickness presence, most students in Latvia reported it being due to attendance pressure to follow absence regulations and get good grades. Belgium and Finland had much lower proportions of students reporting sickness presence. Students from Belgium and Finland referred less often to attendance requirements for their sickness presence since there were no absence limits. However, it was beyond the scope of the study to investigate cross-country differences in detail.

Some of the factors found to be of relevance for high sickness presence corresponded with previous studies. The analysis indicated that those students who were highly motivated about school were more likely to report high sickness presence than students with low school motiva- 
Table 3. Binary logistic regression of the factors influencing high sickness absence among students in the 2017 study ( $\geq 15$ days) in 25 secondary schools in Belgium, Estonia, Finland, Italy and Latvia

\begin{tabular}{|c|c|c|c|}
\hline Variable & $\mathrm{aOR}$ & $95 \% \mathrm{CI}$ & $\mathrm{p}$ \\
\hline Age & 1.09 & $0.98-1.16$ & \\
\hline \multicolumn{4}{|l|}{ Gender } \\
\hline male & 1.00 & & \\
\hline female & 1.40 & $1.19-1.63$ & $*$ \\
\hline \multicolumn{4}{|l|}{ Migratory status } \\
\hline native & 1.00 & & \\
\hline immigrant & 0.95 & $0.71-1.26$ & \\
\hline \multicolumn{4}{|l|}{ Parents' education } \\
\hline low & 1.00 & & \\
\hline high & 1.07 & $0.91-1.25$ & \\
\hline \multicolumn{4}{|l|}{ Education program } \\
\hline academic/technical studies & 1.00 & & \\
\hline vocational studies & 0.71 & $0.59-0.85$ & ** \\
\hline School motivation & 1.09 & $1.01-1.19$ & $*$ \\
\hline \multicolumn{4}{|l|}{ Sickness absence in 2016} \\
\hline no/low & 1.00 & & \\
\hline high & 5.08 & $4.34-5.96$ & ** \\
\hline \multicolumn{4}{|l|}{ Sickness presence in 2016} \\
\hline no/low & 1.00 & & \\
\hline high & 2.08 & $1.71-2.53$ & ** \\
\hline \multicolumn{4}{|l|}{ Study country } \\
\hline Finland & 1.00 & & \\
\hline Belgium & 0.21 & $0.15-0.30$ & ** \\
\hline \multicolumn{4}{|l|}{ Study country - cont. } \\
\hline Estonia & 1.18 & $0.93-1.50$ & \\
\hline Italy & 0.69 & $0.53-0.90$ & ** \\
\hline Latvia & 0.82 & $0.64-1.05$ & \\
\hline
\end{tabular}

* Significant at 0.05 .

** Significant at 0.01 .

tion. The association between school motivation and high sickness presence was also reported in the previous Norwegian study in secondary school [17], whilst work satisfaction and work enjoyment were often reported reasons for sickness presence among adults [3,14-16].
Age was relevant to some extent, as students in their final year reported sickness presence more often than younger students. Similarly, Norwegian students in upper secondary school reported high sickness presence to a greater extent than students in lower secondary school [17]. It is probable that this correlation was related to the desire to get good grades, since grades in the final year were particularly important for admission to higher education and for job/internship applications. In focus group interviews, students in their final year reported that they engaged in sickness presence because they did not want to risk missing crucial information about the course content during their absence, and also because the absence could affect their grades in a negative way.

One reason for investigating sickness presence in school is that attitudes towards absence and presence are something that might follow young people from school to the workplace $[19,20]$. Another reason concerns the possible relationship between sickness presence and sickness absence. Corresponding with findings from previous studies of sickness presence in the adult population $[1,2,7,8]$, and the Norwegian study of sickness presence in secondary school [17], the cross-sectional analysis showed a strong positive correlation between sickness presence and sickness absence (Table 2). Moreover, since data were collected at 2 points in time, the authors were also able to investigate the relationship between high sickness presence and future sickness absence (Table 3). Even when controlling for previous sickness absence and other relevant factors, there was a significant positive association between high sickness presence and high sickness absence in the following year. Thus, corresponding with other studies of working life [8-12], experiencing several incidents of sickness presence during the school year seemed to influence future sickness absence.

The present study has many strengths, such as a good representation of students from different types of 
schools, a large sample and a high response rate. In addition, the survey has enabled simultaneous analyses of many variables of relevance to high sickness presence and high sickness absence. One aspect that is a limitation, however, is the potential for variation regarding students' threshold for considering that they "should" have stayed at home while sick. It may be the case, for example, that respondents from different countries have different thresholds, which could have an impact on the level of sickness presence reported. Responses to questions about sickness presence might also have been influenced by recall bias, which could affect the validity of the results.

\section{CONCLUSIONS}

This article expanded the body of research on sickness presence to include secondary school students. In total, $16 \%$ of secondary school students reported high sickness presence, but there were significant cross-country differences. It would also be interesting with studies that could go more into depth about cross-country differences regarding sickness presence among students. Students with high absence and high school motivation were overrepresented among those reporting high sickness presence. It would be of interest to investigate the reasons for sickness presence among various groups of students, and particularly to examine whether positive reasons (e.g., school enjoyment) or negative reasons for sickness presence (e.g., attendance pressure) matter most for sickness presence in secondary schools. The strong association between sickness absence and sickness presence might suggest that sickness presence is a good indicator of student health, and that efforts to tackle the underlying causes of poor health could help to reduce both sickness presence and sickness absence. Moreover, the study found that experiences of high sickness presence seemed to influence high sickness absence in the following year.

\section{ACKNOWLEDGMENTS}

The author would like to thank all the national ministries and the participating schools for their support with data collection. The author would also like to thank the Eastern Norway Research Institute for technical help with data collection.

\section{REFERENCES}

1. Aronsson G, Gustafsson K, Dallner M. Sick but yet at work. An empirical study of sickness presence. J Epidemiol Community Health. 2000;54(7):502-9, https://doi.org/10.1136/jech. 54.7.502.

2. Whysall Z, Bowden J, Hewitt M. Sickness presenteeism: measurement and management challenges. Ergonomics. 2017;61(3):341-54, https://doi.org/10.1080/00140139.2017.13 65949.

3. Johansen V, Aronsson G, Marklund S. Positive and negative reasons for sickness presenteeism in Norway and Sweden: a cross-sectional survey. BMJ Open. 2014;4(2):e004123, http:/ dx.doi.org/10.1136/bmjopen-2013-004123.

4. Hansen CD, Andersen JH. Going ill to work - what personal circumstances, attitudes and work-related factors are associated with sickness presence? Soc Sci Med. 2008;67(6):956-64, https://doi.org/10.1016/j.socscimed.2008.05.022.

5. Böckerman P, Laukkanen E. What makes you work while you are sick? Evidence from a survey of workers. Eur J Public Health. 2010;20(1):43-6, https://doi.org/10.1093/eurpub/ ckp076.

6. Collins JJ, Baase CM, Sharda CE, Ozminkowski RJ, Nicholson S, Billotti GM, et al. The assessment of chronic health conditions on work performance, absence, and total economic impact for employers. J Occup Environ Med. 2005;47(6):54757, https://doi.org/10.1097/01.jom.0000166864.58664.29.

7. Hemp P. Presenteeism: At work - But out of it. Harv Bus Rev. 2004;82(10):49-58.

8. Hansen CD, Andersen JH. Sick at work - a risk factor for long-term sickness absence at a later date? J Epidemiol Community Health. 2009;63(5):397-402, https://doi.org/10.1136/ jech.2008.078238. 
9. Taloyan M, Aronsson G, Leineweber C, Hanson L, Alexanderson K, Westerlund H. Sickness presence predicts suboptimal self-rated health and sickness absence: A nationally representative study of the Swedish working population. PLoS One. 2012;7(9):e44721, https://doi.org/10.1371/journal.pone. 0044721.

10. Kivimäki M, Head J, Ferrie JE, Hemingway H, Shipley MJ, Vahtera J, et al. Working while ill as a risk factor for serious coronary events: the Whitehall II study. Am J Public Health. 2005;95(1):98-102, https://doi.org/10.2105/AJPH. 2003.035873 .

11. Gustafsson K, Marklund S. Consequences of sickness presence and sickness absence on health and work ability a Swedish prospective cohort study. Int J Occup Med Environ Health. 2011;24(2);153-65, https://doi.org/10.2478/ s13382-011-0013-3.

12. Bergström G, Bodin L, Hagberg J, Aronsson G, Josephson M. Sickness presence today, sickness absenteeism tomorrow? A prospective study on sickness presence and future sickness absenteeism. J Occup Environ Med. 2009;51(6):629-38, https://doi.org/10.1097/JOM.0b013e3181a8281b.

13. Aronsson G, Gustafsson K, Mellner C. Sickness presence, sickness absence, and self-reported health and symptoms. Int J Workplace Health Manag. 2011;4(3):228-43, https:// doi.org/10.1108/17538351111172590.
14. Rostad IS, Milch V, Saksvik PØ. Psychosocial workplace factors associated with sickness presenteeism, sickness absenteeism, and long-term health in a Norwegian industrial company. Scand Psychologist. 2015;2(6):e11, https://doi.org/ 10.15714/scandpsychol.2.e11.

15. Johns G. Presenteeism in the workplace: A review and research agenda. J Organ Behav. 2010;31(4):519-42, https:// doi.org/10.1002/job.630.

16. Marklund S, Aronsson G, Johansen V, Solheim L. Previous sickness presence among long-term sick-listed in Norway and Sweden: A retrospective study of prevalence and self-reported reasons. reasons. Int J Soc Welf. 2014;24(4):376-87, https://doi.org/10.1111/ijsw.12143.

17. Johansen V. Sick and still at school: an empirical study of sickness presence among students in Norwegian secondary school. BMJ Open. 2015;5:e008290, http://dx.doi.org/10.1136/ bmjopen-2015-008290.

18. Field A. Discovering statistics using IBM SPSS statistics. London: Sage Publications; 2013.

19. Eagly AH, Chaiken S. The psychology of attitudes. Fort Worth, TX: Harcourt Brace Jovanovich; 1993.

20. Glasman LR, Albarracin D. Forming attitudes that predict future behaviour: A meta-analysis of the attitude-behavior relation. Psychol Bull. 2006;132(5):778-822, https://doi.org/ 10.1037/0033-2909.132.5.778.

This work is available in Open Access model and licensed under a Creative Commons Attribution-NonCommercial 3.0 Poland License - http://creativecommons.org/ licenses/by-nc/3.0/pl/deed.en. 